Short communication

\title{
A new refractory Ti-Nb-Hf-Al high entropy alloy strengthened by orthorhombic phase particles
}

\author{
N. Yurchenko ${ }^{\mathrm{a}, *}$, E. Panina ${ }^{\mathrm{a}}$, M. Tikhonovsky ${ }^{\mathrm{b}}$, G. Salishchev ${ }^{\mathrm{a}}$, S. Zherebtsov ${ }^{\mathrm{a}}$, N. Stepanov ${ }^{\mathrm{a}}$ \\ ${ }^{a}$ Laboratory of Bulk Nanostructured Materials, Belgorod National Research University, Belgorod 308015, Russia \\ ${ }^{\mathrm{b}}$ National Science Center "Kharkov Institute of Physics and Technology" NAS of Ukraine, Kharkov 61108, Ukraine
}

\section{A R T I C L E I N F O}

\section{Keywords:}

Refractory high-entropy alloy

Precipitation strengthening

Orthorhombic phase

Microstructure

Mechanical properties

CALPHAD

\begin{abstract}
A B S T R A C T
This study reports the structure and mechanical properties of a new refractory $\mathrm{Ti}_{40} \mathrm{Nb}_{30} \mathrm{Hf}_{15} \mathrm{Al}_{15}$ (at.\%) high entropy alloy. The alloy was fabricated by vacuum arc melting and had a density of $7.07 \pm 0.03 \mathrm{~g} / \mathrm{cm}^{3}$. After annealing at $1200{ }^{\circ} \mathrm{C}$ for $24 \mathrm{~h}$, the alloy possessed a single-phase B2 structure. Further annealing at $600{ }^{\circ} \mathrm{C}$ for $24 \mathrm{~h}$ resulted in the formation of Widmanstatten ( $\mathrm{Ti}, \mathrm{Al}$ )-rich orthorhombic particles (O-phase) in a bcc matrix. The single-phase B2 alloy demonstrated high ( $>50 \%$ ) compressive ductility and a pronounced work hardening capacity. The precipitation of the O-phase particles led to a $50 \%$ strength increment at 22 and $600{ }^{\circ} \mathrm{C}$, with some sacrificing in the compressive ductility at $22^{\circ} \mathrm{C}$. The obtained results suggest new approaches to the development of precipitation-strengthened refractory high entropy alloys with a balanced combination of the room- and hightemperature properties.
\end{abstract}

\section{Introduction}

High entropy alloys (HEAs) represent a new class of metallic alloys with a multicomponent design philosophy [1-3]. This concept endows numerous opportunities to develop alloys with a variety of microstructures and properties [4-7]. Recently, HEAs based on refractory elements (RHEAs) have attracted considerable attention due to superb strength at extremely high temperatures [8,9]. RHEAs can possess either a single-phase bcc/B2 structure or multi-phase structures comprising the bcc/B2 phases and intermetallic compounds like the Laves and other phases [9-11]. The conventional approach to the development of high-temperature materials, based on the successful Ni-based superalloys experience, suggests that alloys composed of a disordered matrix and coherent, ordered precipitates can offer balanced properties. In this context, RHEAs consisted of the bcc and B2 phases seem an attractive option. Indeed, some of the alloys with the bcc/B2 phases have demonstrated remarkable specific strength at temperatures up to $1200{ }^{\circ} \mathrm{C}$ [12].

However, most of bcc/B2 RHEAs are brittle since the B2 phase is a continuous matrix with bcc precipitates [12,13]. Only some RHEAs can have a ductile bcc matrix with embedded B2 strengthening particles after proper treatment $[14,15]$. Note that these alloys were obtained by compositional adjustments that pursued different goals, like density reduction or strength increment $[12,16]$. Meanwhile, exploration of the vast composition space of (R)HEA requires using efficient computational tools to predict the structure and properties of alloys. The CALPHAD (CALculation of PHAse Diagrams) approach can provide data on structures of thousands of different alloys in a reasonable time and is suited for (R)HEAs research [17]. However, the available databases lack an accurate description of the B2 phase in refractory alloys [10]. Thus, a precise prognostication and optimization of the bcc/B2 RHEAs by CALPHAD tools are impossible so far.

We used another way to design precipitation-strengthened RHEAs with promising mechanical properties. Some common elements in RHEAs, like Ti, Zr, or Hf, exhibit the $\beta$ (bcc) $\rightarrow \alpha$ (hcp) phase transformation during cooling at 882,863 , or $1743{ }^{\circ} \mathrm{C}$, respectively. In the case of a sufficient amount of these elements in a RHEA, besides the presence of bcc-stabilizing elements of $\mathrm{Nb}$ or $\mathrm{Ta}$, the high-temperature single-phase bcc structure can decompose into a mixture of the bcc and hcp phases at a specific temperature $[18,19]$. Also, if a strong compound-former, like $\mathrm{Al}$, is added, the hcp phase can become an ordered one, thereby providing sufficient strengthening [20].

In this work, the search for bcc-hcp RHEAs was conducted in the Ti$\mathrm{Nb}$-(Zr, Hf)-Al system using the CALPHAD method. The concentration of each component varied from 5 to 40 at.\% with a step of 5 at.\%. Based on the analysis of several dozens of calculated equilibrium phase diagrams, the alloys with a high-temperature single-phase bcc field followed by a bcc + hcp field at lower temperatures were found, and a

\footnotetext{
* Corresponding author at: Laboratory of Bulk Nanostructured Materials, Belgorod National Research University, Pobeda 85, Belgorod 308015, Russia.

E-mail address: yurchenko_nikita@bsu.edu.ru (N. Yurchenko).
} 
Table 1

Measured chemical composition of the structural constituents in the $\mathrm{Ti}_{40} \mathrm{Nb}_{30} \mathrm{Hf}_{15} \mathrm{Al}_{15}$ alloy.

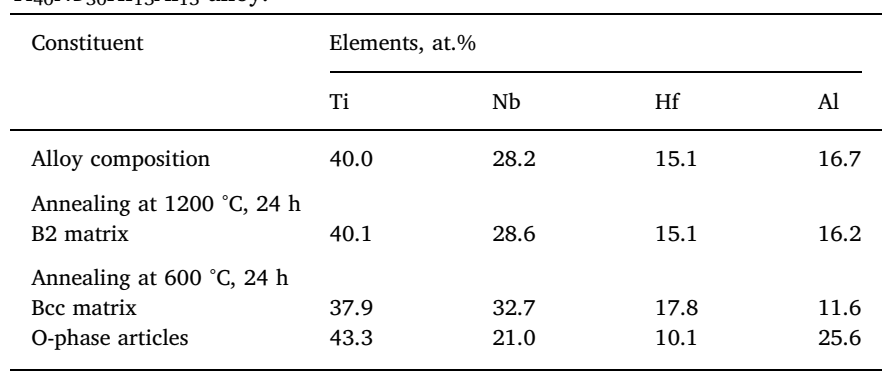

$\mathrm{Ti}_{40} \mathrm{Nb}_{30} \mathrm{Hf}_{15} \mathrm{Al}_{15}$ (at.\%) alloy was chosen as a proof of concept.

\section{Materials and methods}

An ingot of the $\mathrm{Ti}_{40} \mathrm{Nb}_{30} \mathrm{Hf}_{15} \mathrm{Al}_{15}$ alloy with dimensions of $10 \times 15 \times 40 \mathrm{~mm}^{3}$ was produced by vacuum arc melting of pure $(\geq$ $99.9 \mathrm{wt} \%$ ) elements in a high purity argon atmosphere; the actual chemical composition is listed in Table 1 . Rectangular samples measured $6 \times 4 \times 4 \mathrm{~mm}^{3}$ were cut from the as-cast ingot and annealed at $1200{ }^{\circ} \mathrm{C}$ for $24 \mathrm{~h}$. Some samples were further annealed at $600{ }^{\circ} \mathrm{C}$ for $24 \mathrm{~h}$. Before the annealing, the samples were encapsulated in vacuumed $\left(10^{-2}\right.$ Torr) quartz tubes filled with titanium chips to prevent any oxidation. Cooling after the annealing was carried out in laboratory air.

The phase composition and microstructure of the alloy were studied using X-ray diffraction (XRD), scanning electron microscopy (SEM), and transmission electron microscopy (TEM). Samples for SEM and XRD analysis were prepared by careful mechanical polishing. XRD analysis was performed using a RIGAKU diffractometer and $\mathrm{Cu} \mathrm{Ka}$ radiation having the wavelength $1.5406 \AA$ and a scanning rate of $3^{\circ} / \mathrm{min}$ from $20^{\circ}$ to $125^{\circ}$. SEM investigations were carried out on an FEI Quanta 600 FEG or Nova NanoSEM 450 microscopes equipped with an energy-dispersive (EDS) detector. Mechanically pre-thinned to $100 \mu \mathrm{m}$ foils were prepared for TEM analysis by conventional twin-jet electro-polishing at a temperature of $-35{ }^{\circ} \mathrm{C}$ and an applied voltage of $29.5 \mathrm{~V}$ in a mixture of $600 \mathrm{ml}$ of methanol, $360 \mathrm{ml}$ of butanol, and $60 \mathrm{ml}$ of perchloric acid. TEM investigations were performed using a JEOL JEM-2100 microscope equipped with an EDS detector.

The density of the alloy, determined by the hydrostatic weighing method, was $7.07 \pm 0.03 \mathrm{~g} / \mathrm{cm}^{3}$. Isothermal compression of rectangular samples measured $6 \times 4 \times 4 \mathrm{~mm}^{3}$ was carried out in air at $22{ }^{\circ} \mathrm{C}$ or $600{ }^{\circ} \mathrm{C}$ using an Instron $300 \mathrm{LX}$ test machine equipped with a radial furnace. The samples tested at $600{ }^{\circ} \mathrm{C}$ were placed into the preheated furnace and held for $\approx 10 \mathrm{~min}$ to equilibrate the temperature before testing. The temperature of the samples was controlled by a thermocouple attached to a side surface of the specimen. The initial strain rate was $10^{-4} \mathrm{~s}^{-1}$.

Thermodynamic modeling of the alloy was performed using a Thermo-Calc (version 2020a) software and a TCHEA3 (high-entropy alloys) database.

\section{Results}

Fig. 1 illustrates the equilibrium phase diagram of the $\mathrm{Ti}_{40} \mathrm{Nb}_{30} \mathrm{Hf}_{15} \mathrm{Al}_{15}$ alloy. The alloy should solidify through a bcc phase at temperatures of $1595-1800{ }^{\circ} \mathrm{C}$; meanwhile, a (Ti, Zr)-rich hcp phase is expected at $760{ }^{\circ} \mathrm{C}$. At lower temperatures $\left(685^{\circ} \mathrm{C}\right.$ and $\left.545^{\circ} \mathrm{C}\right), \mathrm{Hf}_{3} \mathrm{Al}_{2}$ and $\mathrm{Ti}_{3} \mathrm{Al}$ phases with the chemical compositions close to the stoichiometric ones should precipitate, respectively.

Fig. 2 presents the XRD patterns of the $\mathrm{Ti}_{40} \mathrm{Nb}_{30} \mathrm{Hf}_{15} \mathrm{Al}_{15}$ alloy. After annealing at $1200{ }^{\circ} \mathrm{C}$, the alloy had a single-phase B2 structure with the lattice parameter $\mathrm{a}=0.3304 \pm 0.0004 \mathrm{~nm}$. The microstructure

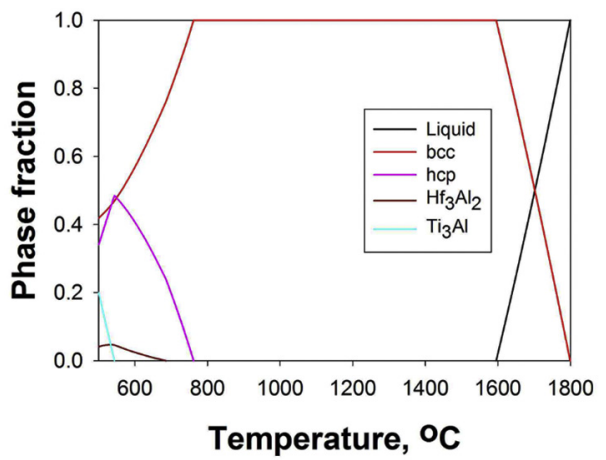

Fig. 1. Equilibrium phase diagram of the $\mathrm{Ti}_{40} \mathrm{Nb}_{30} \mathrm{Hf}_{15} \mathrm{Al}_{15}$ alloy.

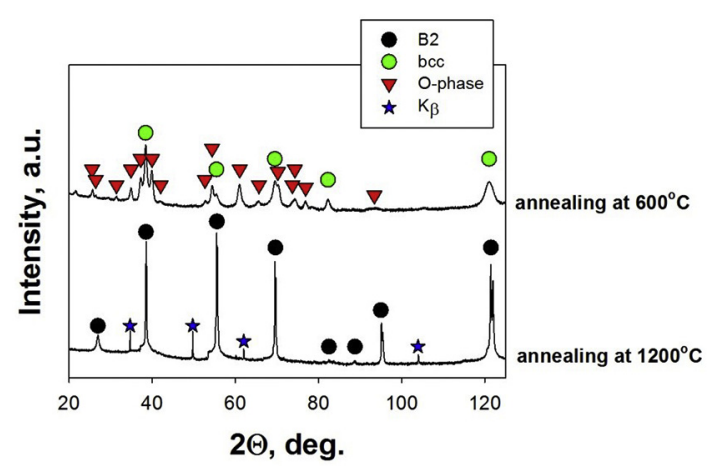

Fig. 2. XRD patterns of the $\mathrm{Ti}_{40} \mathrm{Nb}_{30} \mathrm{Hf}_{15} \mathrm{Al}_{15}$ alloy after annealing at $1200{ }^{\circ} \mathrm{C}$ and further annealing at $600{ }^{\circ} \mathrm{C}$.

consisted of coarse $(\sim 400 \mu \mathrm{m})$ polygonal-shaped grains with clear boundaries (see a magnified insert in Fig. 3a); the average chemical composition of the grains corresponded closely to the nominal composition (Fig. 3a, Table 1). TEM analysis confirmed the B2 ordering and revealed numerous anti-phase boundaries in the matrix grains (denoted in Fig. $3 \mathrm{~b}$ as APBs); no secondary phases were detected.

After further annealing at $600{ }^{\circ} \mathrm{C}$, which was found to increase the hardness of the alloy noticeably according to preliminary studies, the structure, however, consisted of the bcc and orthorhombic $(\mathrm{Cmcm}-$ space group; hereafter denoted as the O-phase) phases (Fig. 2). The lattice parameters of the bcc and O-phases were determined as $\mathrm{a}=0.3311 \pm 0.0003 \mathrm{~nm}$ and $\mathrm{a}=0.6068 \pm 0.0002 \mathrm{~nm}$, $\mathrm{b}=0.9648 \pm 0.0003 \mathrm{~nm}, \mathrm{c}=0.4710 \pm 0.0003 \mathrm{~nm}$, respectively.

The microstructure after annealing at $600{ }^{\circ} \mathrm{C}$ comprised profuse fine Widmanstatten second phase particles inside large $(\sim 400 \mu \mathrm{m})$ matrix grains (Fig. 3c). The precipitates were somewhat coarser in regions adjacent to the grain boundaries. Both phases were identified using TEM analysis: the matrix had the bcc structure, and the needle-like particles were the O-phase; no signs of other phases were found (Fig. 3d). Some round O-phase particles were also observed (dark dots in Fig. 3d); the variation in the shape of the particles could be associated with different orientations with respect to the cross-section surface (so-called stereological effect). The average transversal and longitudinal sizes of the O-phase particles were $22 \pm 8$ and $230 \pm 70 \mathrm{~nm}$, respectively. The volume fraction of these particles was $35 \pm 3 \%$. The selected area electron diffraction (SAED) pattern at the insert in Fig. 3d indicated a $[001]_{\mathrm{bcc}}\left\|[100]_{\mathrm{O}},(110)_{\mathrm{bcc}}\right\|(001)_{\mathrm{O}}$ orientation relationship (OR) between the bcc matrix and O-phase particles. A TEM dark-field image revealed that the O-phase also had an additional $[021]_{\text {bcc }}||[1 \overline{1} 2]_{\mathrm{O}},(1 \overline{1} 2)_{\text {bcc }} \|(110)_{\mathrm{O}}$ OR with the bcc matrix (Fig. 3e). According to EDS analysis, the O-phase was enriched with $\mathrm{Ti}$ and $\mathrm{Al}$ and depleted of $\mathrm{Hf}$ and $\mathrm{Nb}$ (Table 1 ).

Fig. 4 depicts the engineering stress-strain curves of the $\mathrm{Ti}_{40} \mathrm{Nb}_{30} \mathrm{Hf}_{15} \mathrm{Al}_{15}$ alloy obtained during compression at 22 and $600{ }^{\circ} \mathrm{C}$; 


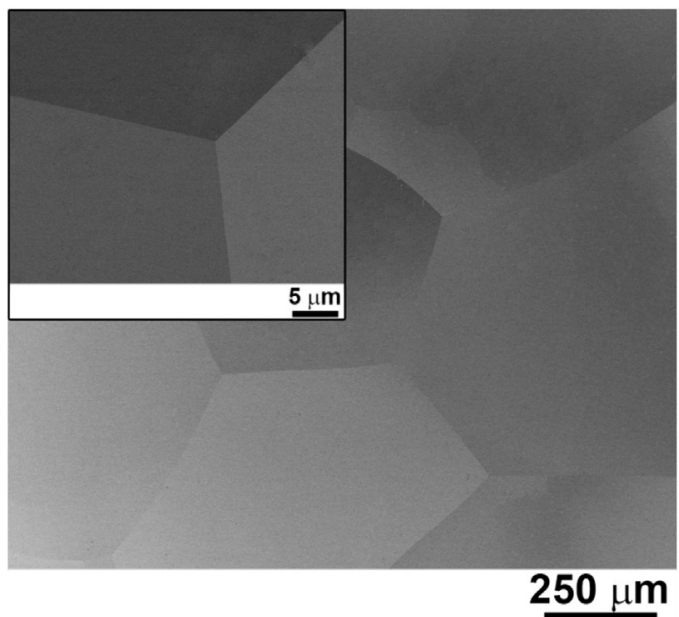

$\mathrm{a}$

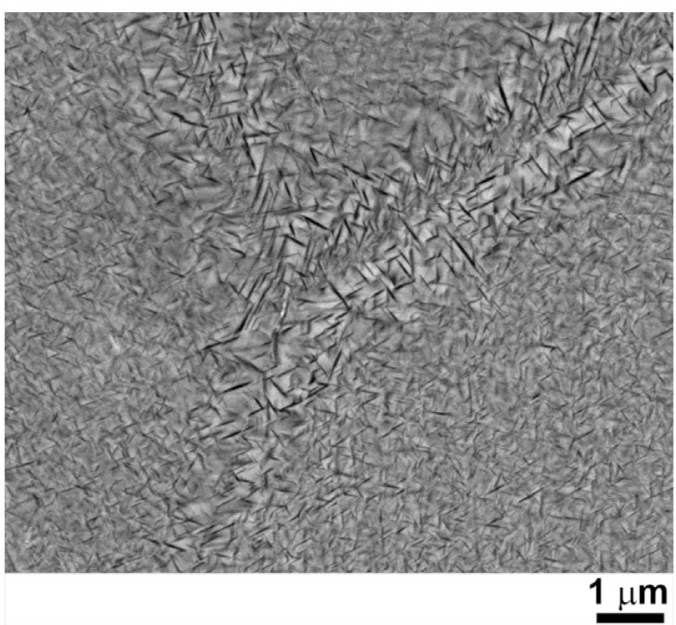

C

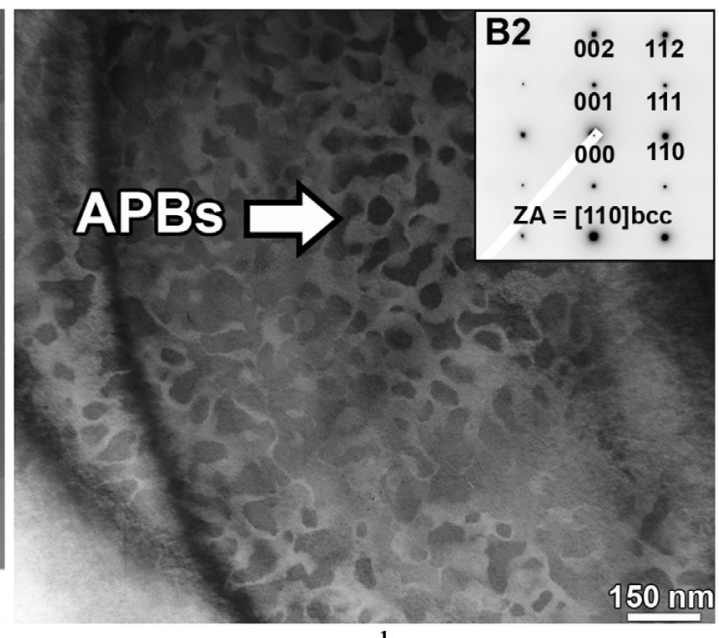

b

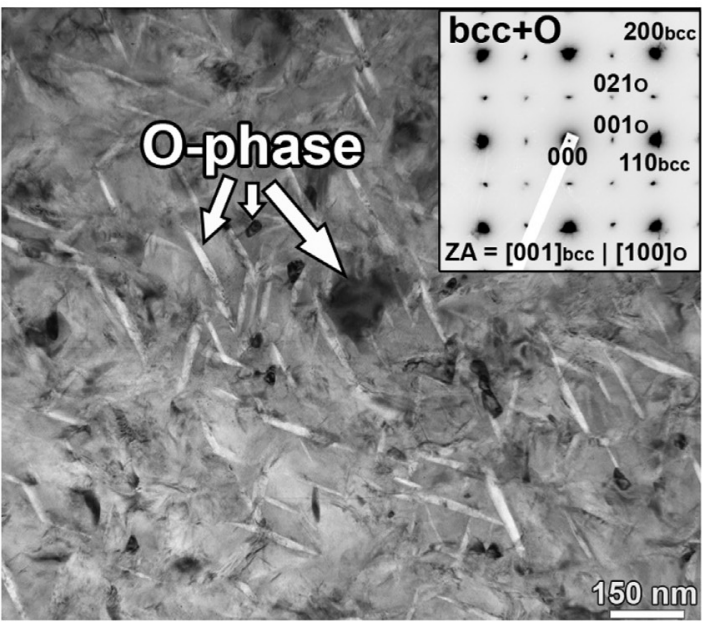

d

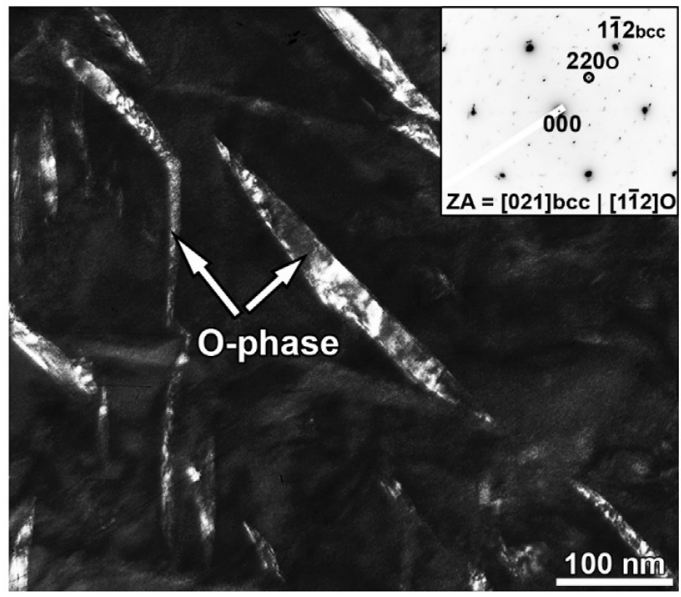

e

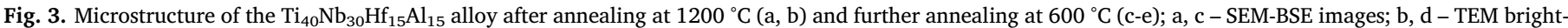

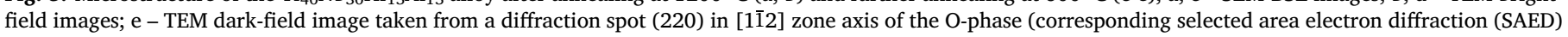
pattern) is shown in the inset).

Table 2 summarizes data on the mechanical properties of the alloy. After annealing at $1200{ }^{\circ} \mathrm{C}$, the alloy demonstrated the yield strength of $830 \mathrm{MPa}$ and high compressive ductility ( $>50 \%$ ) at room temperature (Fig. 4a, Table 2). Note, the alloy showed pronounced work hardening.
At $600{ }^{\circ} \mathrm{C}$, the yield strength decreased to $635 \mathrm{MPa}$, but the alloy retained the same work hardening capacity and high ductility (Fig. 4b).

Annealing at $600{ }^{\circ} \mathrm{C}$ changed the mechanical properties of the alloy noticeably (Fig. 4, Table 2). At $22{ }^{\circ} \mathrm{C}$, the yield strength increased by 


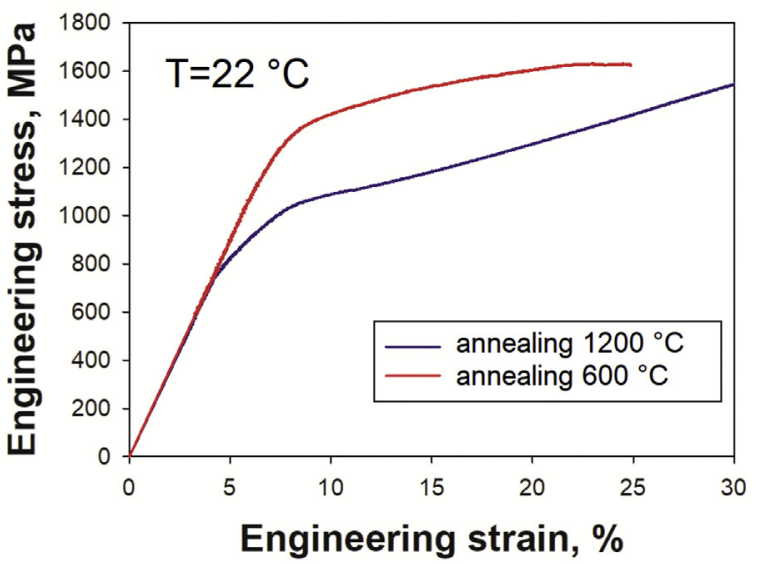

a

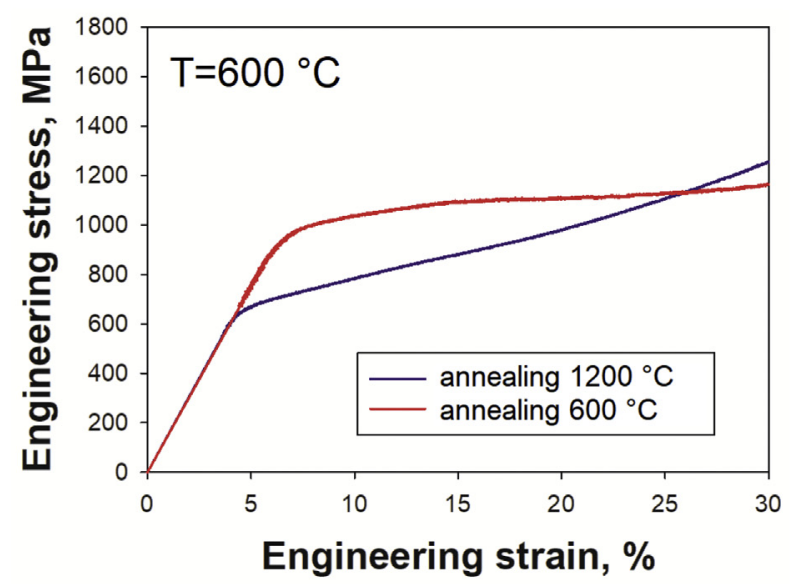

b

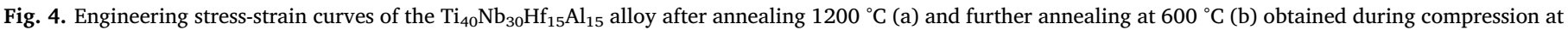
22 and $600{ }^{\circ} \mathrm{C}$.

Table 2

Mechanical properties ( $\sigma_{\mathrm{YS}}$ - yield strength, $\sigma_{\mathrm{p}}$ - peak strength, $\varepsilon$ - compressive ductility) of the $\mathrm{Ti}_{40} \mathrm{Nb}_{30} \mathrm{Hf}_{15} \mathrm{Al}_{15}$ alloy after annealing $1200{ }^{\circ} \mathrm{C}$ and further annealing at $600{ }^{\circ} \mathrm{C}$ obtained during compression at 22 and $600{ }^{\circ} \mathrm{C}$.

\begin{tabular}{|c|c|c|c|c|c|c|}
\hline \multirow[t]{3}{*}{ Condition } & \multicolumn{6}{|c|}{ Compression temperature, ${ }^{\circ} \mathrm{C}$} \\
\hline & \multicolumn{3}{|l|}{22} & \multicolumn{3}{|l|}{600} \\
\hline & $\sigma_{\mathrm{YS}}, \mathrm{MPa}$ & $\sigma_{\mathrm{p}}, \mathrm{MPa}$ & $\varepsilon, \%$ & $\sigma_{\mathrm{YS}}, \mathrm{MPa}$ & $\sigma_{\mathrm{p}}, \mathrm{MPa}$ & $\varepsilon, \%$ \\
\hline $\begin{array}{l}\text { Annealing at } 1200{ }^{\circ} \mathrm{C} \text {, } \\
24 \mathrm{~h}\end{array}$ & 830 & - & $>50$ & 635 & - & $>50$ \\
\hline $\begin{array}{l}\text { Annealing at } 600{ }^{\circ} \mathrm{C} \text {, } \\
\quad 24 \mathrm{~h}\end{array}$ & 1250 & 1630 & 16 & 920 & - & $>50$ \\
\hline
\end{tabular}

$\sim 50 \%$ to $1250 \mathrm{MPa}$; the ductility reduced but maintained at a moderate level of $16 \%$ (Fig. 4a). At $600{ }^{\circ} \mathrm{C}$, the alloy exhibited higher ductility ( $>50 \%)$ and a strength increment ( $45 \%)$ comparable to room-temperature; as a result, the yield strength raised to $920 \mathrm{MPa}$ (Fig. 4b).

\section{Discussion}

The presented results demonstrate that the predicted and experimental structures of the $\mathrm{Ti}_{40} \mathrm{Nb}_{30} \mathrm{Hf}_{15} \mathrm{Al}_{15}$ RHEA differ a lot (Figs. 1-3). As the CALPHAD approach fails to prognosticate the $\mathrm{B} 2$ and O-phases, we try to analyze the observed phase compositions and transformations using existing data on simpler systems. The B2 and O-phases can be found in the ternary Al-Nb-Ti system [21]; however, the Hf-containing ternaries, like $\mathrm{Al}-\mathrm{Nb}-\mathrm{Hf}$ or $\mathrm{Al}-\mathrm{Hf}-\mathrm{Ti}$, are available for only narrow concentration and temperature ranges [22,23]. Note, the TCHEA3 database lacks the description of Al-Nb-Ti and Al-Nb-Hf ternaries and tentatively assesses only the Al-Hf-Ti [24]. Replacing Hf with other elements of the $\mathrm{Ti}_{40} \mathrm{Nb}_{30} \mathrm{Hf}_{15} \mathrm{Al}_{15}$ RHEA can generate the following hypothetical alloys: $T i_{55} \mathrm{Nb}_{30} \mathrm{Al}_{15}, \mathrm{Ti}_{40} \mathrm{Nb}_{45} \mathrm{Al}_{15}$, and $\mathrm{Ti}_{40} \mathrm{Nb}_{30} A l_{30}$. In the high-temperature field $\left(1200{ }^{\circ} \mathrm{C}\right)$, only the $\mathrm{Ti}_{40} \mathrm{Nb}_{30} \mathrm{Al}_{30}$ should contain the $\mathrm{B} 2$ phase (and the $\sigma$ phase), according to the Al-Nb-Ti phase diagram [21], whereas the $T_{55} \mathrm{Nb}_{30} \mathrm{Al}_{15}$ and $\mathrm{Ti}_{40} \mathrm{Nb}_{45} \mathrm{Al}_{15}$ should have single-phase bcc structures. It indicates that Hf plays a significant role, along with $\mathrm{Al}$, in stabilizing the $\mathrm{B} 2$ structure in the Ti-Nb-Hf-Al system. This finding seems essential in the context of further search for B2strengthened RHEAs.

Meanwhile, the B2 phase decomposes into the bcc $+\mathrm{O}$ mixture at $600{ }^{\circ} \mathrm{C}$. Various scenarios of transformation pathways in the program alloy can be proposed, including (i) B2 $\rightarrow$ bcc + O; (ii) B2 $\rightarrow$ bcc $\rightarrow$
$\mathrm{bcc}+\mathrm{O}$; (iii) $\mathrm{B} 2 \rightarrow \mathrm{B} 2+\mathrm{O} \rightarrow \mathrm{bcc}+\mathrm{O}$. Both data on the Al-Nb-Ti system and the resemblance of microstructure features of the $\mathrm{Ti}_{40} \mathrm{Nb}_{30} \mathrm{Hf}_{15} \mathrm{Al}_{15}$ RHEA to those of $\mathrm{Ti}_{2} \mathrm{AlNb}$-based alloys [25] suggest the $\mathrm{B} 2 \rightarrow \mathrm{bcc}+\mathrm{O}$ transition as the most probable one. Furthermore, two of the above mentioned hypothetical alloys, namely $T_{55} \mathrm{Nb}_{30} \mathrm{Al}_{15}$ and $\mathrm{Ti}_{40} \mathrm{Nb}_{45} \mathrm{Al}_{15}$, locate in a bcc $+\mathrm{O}$ field at $700^{\circ} \mathrm{C}$ (the lowest accessed temperature in the ternary $\mathrm{Al}-\mathrm{Nb}-\mathrm{Ti}$ system) [21]. In turn, the $\mathrm{Ti}_{40} \mathrm{Nb}_{30} \mathrm{Al}_{30}$ alloy should belong to a single O-field. This analysis means that $\mathrm{Hf}$ in the Ti-Nb-Hf-Al system behaves somewhat identically to $\mathrm{Ti}$ or $\mathrm{Nb}$ in terms of the effect on phase stability at relatively low temperatures, contrary to the high temperature of $1200{ }^{\circ} \mathrm{C}$, where $\mathrm{Hf}$ stabilizes the B2 phase, like Al.

Probably, the complex interactions between the elements in the Ti$\mathrm{Nb}-\mathrm{Hf}-\mathrm{Al}$ system, with tentatively accessed ternary compositions, have resulted in considerable differences between the predicted phase diagram (Fig. 1) and the experimental results (Figs. 2, 3). Nevertheless, the initial goal of the development of new RHEA with the bcc matrix precipitation-strengthened by other than the B2 phase was successfully achieved.

Note that the O-phase precipitation instead of expected hcp is not necessarily harmful in terms of mechanical properties. In $\mathrm{Ti}_{2} \mathrm{AlNb}$ based alloys, the O-phase is the main strengthening phase [26]. In the $\mathrm{Ti}_{40} \mathrm{Nb}_{30} \mathrm{Hf}_{15} \mathrm{Al}_{15}$ alloy, annealing at $600{ }^{\circ} \mathrm{C}$ resulted in a substantial increase in strength (Fig. 4, Table 2), most probably, due to the precipitation of the O-phase particles. The contribution of the O-phase to the overall strength can be estimated following a modified Ashby-Orowan equation [27]:

$\Delta \sigma_{O-\text { phase }}=\frac{0.538 G b}{2.36 \pi} \ln \left(\frac{0.57 D S^{\frac{1}{3}}}{b}\right) \frac{1}{\left(0.92 V^{-\frac{1}{3}}-1.14\right) D S^{\frac{1}{3}}}$

where $\mathrm{G}$ is the shear modulus ( $\mathrm{G}=37.4 \mathrm{GPa}$ ) calculated using the rule of mixture; $b$ is the Burgers vector $(b=0.287 \mathrm{~nm}$ ) estimated using the experimental bcc lattice parameter; $S$ is the aspect ratio of O-phase particles $(S=10.5)$; $\mathrm{D}$ is the transversal size of the O-phase particles; $\mathrm{V}$ is the volume fraction of the O-phase particles. The $\mathrm{D}$ and $\mathrm{V}$ values were given above.

The calculated strength increment was $\Delta \sigma_{\text {O-phase }} \approx 445 \mathrm{MPa}$. This value is in good agreement with the experimental increase in strength (420 MPa at room temperature) and proves a dominant role of O-phase particles in strengthening. Note, the O-phase in the $\mathrm{Ti}_{40} \mathrm{Nb}_{30} \mathrm{Hf}_{15} \mathrm{Al}_{15}$ alloy remains an effective reinforcement even at elevated temperature.

Another interesting finding of this work is associated with the high ductility of the program alloy with the single-phase B2 structure. 
Preliminary studies (results not shown here) have revealed that the alloy with the B2 structure can be easily thermomechanically processed by cold rolling and subsequent annealing. Usually, RHEAs with such a structure suffer from brittleness at room temperature [28,29]. However, there are some examples of relatively ductile alloys with nearly a single-phase B2 structure [28,30,31]. The present study confirms that RHEAs with the B2 structure are not necessarily brittle. Yet, identification of the nature of unexpected ductility of the $\mathrm{Ti}_{40} \mathrm{Nb}_{30} \mathrm{Hf}_{15} \mathrm{Al}_{15}$ alloy with the single-phase B2 structure is beyond the scope of the current paper.

\section{Conclusions}

The introduced $\mathrm{Ti}_{40} \mathrm{Nb}_{30} \mathrm{Hf}_{15} \mathrm{Al}_{15}$ alloy demonstrated some unique for RHEAs features. The alloy after annealing at $1200{ }^{\circ} \mathrm{C}$ composed of the single B2 phase that transformed after further annealing at $600{ }^{\circ} \mathrm{C}$ into a mixture of the bcc matrix and Widmanstatten ( $\mathrm{Ti}, \mathrm{Al}$ )-rich $\mathrm{O}$ phase particles with the $[001]_{\mathrm{bcc}}\left\|[100]_{\mathrm{O}},(110)_{\mathrm{bcc}}\right\|(001)_{\mathrm{O}}$ and $[021]_{\mathrm{bcc}} \|[1 \overline{1} 2]_{\mathrm{O}},(1 \overline{1} 2)_{\mathrm{bcc}}||(110)_{\mathrm{O}}$ ORs. The single-phase B2 structure had surprisingly high compression ductility along with moderate strength at room and elevated temperatures. The O-phase precipitation resulted in a considerable increase $(\sim 50 \%)$ in yield strength both at 22 and $600{ }^{\circ} \mathrm{C}$. Even after precipitation of the O-phase, the alloy had sufficient ductility at room temperature. The obtained results suggest new approaches to the development of precipitation-strengthened RHEAs with a balanced combination of the room- and high-temperature properties. Meanwhile, further studies are required to evaluate the effect of composition on the stability of the bcc $+\mathrm{O}$ structure and properties, including mechanical properties at room and elevated temperatures and environmental resistance, of the Ti-Nb-Hf-Al-based RHEAs.

\section{Declaration of Competing Interest}

The authors declare that they have no known competing financial interests or personal relationships that could have appeared to influence the work reported in this paper.

\section{Acknowledgement}

The authors gratefully acknowledge the financial support from the Russian Science Foundation Grant no. 19-79-30066. The authors are grateful to the personnel of the Joint Research Center, "Technology and Materials", Belgorod National Research University, for their assistance.

\section{References}

[1] J.W. Yeh, S.K. Chen, S.J. Lin, J.Y. Gan, T.S. Chin, T.T. Shun, C.H. Tsau, S.Y. Chang, Nanostructured high-entropy alloys with multiple principal elements: novel alloy design concepts and outcomes, Adv. Eng. Mater. 6 (2004) 299-303+274, https:// doi.org/10.1002/adem.200300567.

[2] Y. Zhang, T.T. Zuo, Z. Tang, M.C. Gao, K.A. Dahmen, P.K. Liaw, Z.P. Lu, Microstructures and properties of high-entropy alloys, Prog. Mater. Sci. 61 (2014) 1-93, https://doi.org/10.1016/j.pmatsci.2013.10.001.

[3] D.B. Miracle, O.N. Senkov, A critical review of high entropy alloys and related concepts, Acta Mater. 122 (2017) 448-511, https://doi.org/10.1016/j.actamat. 2016.08.081.

[4] Y.L. Chou, J.W. Yeh, H.C. Shih, The effect of molybdenum on the corrosion behaviour of the high-entropy alloys Co1.5CrFeNi1.5Ti0.5Mox in aqueous environments, Corros. Sci. 52 (2010) 2571-2581, https://doi.org/10.1016/j.corsci.2010. 04.004.

[5] C. Chen, H. Zhang, Y. Fan, W. Zhang, R. Wei, T. Wang, T. Zhang, F. Li, A novel ultrafine-grained high entropy alloy with excellent combination of mechanical and soft magnetic properties, J. Magn. Magn. Mater. 502 (2020) 166513, , https://doi. org /10.1016/j.jmmm.2020.166513.

[6] W.Y. Ching, S. San, J. Brechtl, R. Sakidja, M. Zhang, P.K. Liaw, Fundamental electronic structure and multiatomic bonding in 13 biocompatible high-entropy alloys, Npj Comput. Mater. 6 (2020) 1-10, https://doi.org/10.1038/s41524-0200321-x.

[7] T. Yang, C. Li, S.J. Zinkle, S. Zhao, H. Bei, Y. Zhang, Irradiation responses and defect behavior of single-phase concentrated solid solution alloys, J. Mater. Res. 33 (2018) 3077-3091, https://doi.org/10.1557/jmr.2018.285.

[8] O.N. Senkov, G.B. Wilks, D.B. Miracle, C.P. Chuang, P.K. Liaw, Refractory highentropy alloys, Intermetallics. 18 (2010) 1758-1765, https://doi.org/10.1016/j. intermet.2010.05.014.

[9] O.N. Senkov, D.B. Miracle, K.J. Chaput, Development and exploration of refractory high entropy alloys - a review, J. Mater. Res. (2018), https://doi.org/10.1557/ jmr.2018.153.

[10] N.Y. Yurchenko, N.D. Stepanov, A.O. Gridneva, M.V. Mishunin, G.A. Salishchev, S.V. Zherebtsov, Effect of $\mathrm{Cr}$ and $\mathrm{Zr}$ on phase stability of refractory Al-Cr-Nb-Ti-V-Zr high-entropy alloys, J. Alloys Compd. 757 (2018) 403-414, https://doi.org/10. 1016/j.jallcom.2018.05.099.

[11] H. Chen, A. Kauffmann, S. Seils, T. Boll, C.H. Liebscher, I. Harding, K.S. Kumar, D.V. Szabó, S. Schlabach, S. Kauffmann-Weiss, F. Müller, B. Gorr, H.J. Christ, M. Heilmaier, Crystallographic ordering in a series of Al-containing refractory high entropy alloys Ta-Nb-Mo-Cr-Ti-Al, Acta Mater. 176 (2019) 123-133, https://doi. org/10.1016/j.actamat.2019.07.001.

[12] O.N. Senkov, S.V. Senkova, C. Woodward, Effect of aluminum on the microstructure and properties of two refractory high-entropy alloys, Acta Mater. 68 (2014) 214-228, https://doi.org/10.1016/j.actamat.2014.01.029.

[13] D. Schliephake, A.E. Medvedev, M.K. Imran, S. Obert, D. Fabijanic, M. Heilmaier, A. Molotnikov, X. Wu, Precipitation behaviour and mechanical properties of a novel Al0.5MoTaTi complex concentrated alloy, Scr. Mater. 173 (2019) 16-20, https:// doi.org/10.1016/J.SCRIPTAMAT.2019.07.033.

[14] O.N. Senkov, J.K. Jensen, A.L. Pilchak, D.B. Miracle, H.L. Fraser, Compositional variation effects on the microstructure and properties of a refractory high-entropy superalloy AlMo0.5NbTa0.5TiZr, Mater. Des. 139 (2018) 498-511, https://doi.org/ 10.1016/j.matdes.2017.11.033.

[15] V. Soni, O.N. Senkov, B. Gwalani, D.B. Miracle, R. Banerjee, Microstructural design for improving ductility of an initially brittle refractory high entropy alloy, Sci. Rep. (2018) 1-10, https://doi.org/10.1038/s41598-018-27144-3.

[16] O.N. Senkov, C. Woodward, D.B. Miracle, Microstructure and properties of aluminum-containing refractory high-entropy alloys, Jom. 66 (2014) 2030-2042, https://doi.org/10.1007/s11837-014-1066-0.

[17] O.N. Senkov, J.D. Miller, D.B. Miracle, C. Woodward, Accelerated exploration of multi-principal element alloys with solid solution phases, Nat. Commun. 6 (2015), https://doi.org/10.1038/ncomms7529.

[18] S.Y. Chen, Y. Tong, K.K. Tseng, J.W. Yeh, J.D. Poplawsky, J.G. Wen, M.C. Gao, G. Kim, W. Chen, Y. Ren, R. Feng, W.D. Li, P.K. Liaw, Phase transformations of HfNbTaTiZr high-entropy alloy at intermediate temperatures, Scr. Mater. 158 (2019) 50-56, https://doi.org/10.1016/j.scriptamat.2018.08.032.

[19] N.D. Stepanov, N.Y. Yurchenko, S.V. Zherebtsov, M.A. Tikhonovsky, G.A. Salishchev, Aging behavior of the HfNbTaTiZr high entropy alloy, Mater. Lett. 211 (2018) 87-90, https://doi.org/10.1016/j.matlet.2017.09.094.

[20] L. Rogal, P. Bobrowski, F. Körmann, S. Divinski, F. Stein, B. Grabowski, Computationally-driven engineering of sublattice ordering in a hexagonal AlHfScTiZr high entropy alloy, Sci. Rep. 7 (2017) 1-14, https://doi.org/10.1038/ s41598-017-02385-w.

[21] L. Tretyachenko, M. Materials Science International Team, Al-Nb-Ti Ternary Phase Diagram Evaluation · Phase Diagrams, Crystallographic and Thermodynamic Data: Datasheet from MSI Eureka in SpringerMaterials, https://materials.springer.com/ msi/docs/sm_msi_r_10_016070_02, (2004) https://materials.springer.com/msi/ docs/sm msi_r 1001607002

[22] O. Kubaschewski, M. Materials Science International Team, Al-Hf-Nb Ternary Phase Diagram Evaluation · Phase Diagrams, Crystallographic and Thermodynamic Data: Datasheet from MSI Eureka in SpringerMaterials, https://materials.springer.com/ msi/docs/sm msi r 10016066 01, (1993) https://materials.springer.com/msi/ docs/sm_msir_ 10_016066 01 .

[23] F.H. Hayes, M. Materials Science International Team, Al-Hf-Ti Ternary Phase Diagram Evaluation · Phase diagrams, crystallographic and thermodynamic data: Datasheet from MSI Eureka in SpringerMaterials, https://materials.springer.com/ msi/docs/sm msi r 10012748 01, (1993).

[24] TCHEA3: TCS High Entropy Alloy Database, n.d www.thermocalc.com, (2020) (accessed May 1, 2020).

[25] D. Banerjee, The intermetallic Ti2AlNb, Prog. Mater. Sci. 42 (1997) 135-158, https://doi.org/10.1016/s0079-6425(97)00012-1.

[26] C.J. Boehlert, Part III. The tensile behavior of Ti-Al-Nb O Bcc orthorhombic alloys, Metall. Mater. Trans. A. 32 (2001) 1977-1988.

[27] B. Chen, J. Shen, X. Ye, L. Jia, S. Li, J. Umeda, M. Takahashi, K. Kondoh, Length effect of carbon nanotubes on the strengthening mechanisms in metal matrix composites, Acta Mater. 140 (2017) 317-325, https://doi.org/10.1016/j.actamat. 2017.08.048.

[28] N.Y. Yurchenko, N.D. Stepanov, S.V. Zherebtsov, M.A. Tikhonovsky, G.A. Salishchev, Structure and mechanical properties of B2 ordered refractory AlNbTiVZrx (x=0-1.5) high-entropy alloys, Mater. Sci. Eng. A 704 (2017) 82-90, https://doi.org/10.1016/j.msea.2017.08.019.

[29] S. Laube, H. Chen, A. Kauffmann, S. Schellert, F. Müller, B. Gorr, J. Müller, B. Butz, H.J. Christ, M. Heilmaier, Controlling crystallographic ordering in Mo-Cr-Ti-Al high entropy alloys to enhance ductility, J. Alloys Compd. 823 (2020) 153805, , https://doi.org/10.1016/j.jallcom.2020.153805.

[30] W. Chen, Q.H. Tang, H. Wang, Y.C. Xie, X.H. Yan, P.Q. Dai, Microstructure and mechanical properties of a novel refractory AlNbTiZr high-entropy alloy, Mater. Sci. Technol. 34 (2018) 1309-1315, https://doi.org/10.1080/02670836.2018. 1446267.

[31] S. Zherebtsov, N. Yurchenko, E. Panina, M. Tikhonovsky, N. Stepanov, Gum-like mechanical behavior of a partially ordered Al5Nb24Ti40V5Zr26 high entropy alloy, Intermetallics. 116 (2020) 106652, , https://doi.org/10.1016/j.intermet.2019. 106652. 